CARVALHO, José Murilo de. 2005 (2001). Cidadania no Brasil - o longo caminho. $7^{\text {a }}$ ed. Rio de Janeiro : Civilização Brasileira.

\title{
DIREITOS NO BRASIL: NECESSIDADE DE UM CHOQUE DE CIDADANIA
}

\author{
Venceslau Alves de Souza
}

A questão dos direitos no Brasil parece nunca ter sido tão atual. Quanto mais se avança em direção ao aprimoramento das instituições democráticas, menos fica evidente o usufruto do tripé dos direitos que lhe dão sustentação. A pobreza aguda de mais de 25 milhões de brasileiros, segundo dados do IBGE, ratifica nosso gap irresoluto na consolidação dos direitos sociais. A histérica falta de segurança faz-nos lembrar que o direito civil de ir e vir está ameaçado a cada vez que nos aventuramos em sair de casa. Os direitos políticos parecem mais fortemente consolidados, embora tratemos de um país onde a prática endógena do exercício democrático é coisa nova. Daí a importância e a justificativa de resenhar-se uma obra como esta, cuja importância pode ser avaliada por seu êxito editorial: lançada em 2001, em 2005 já alcançava sua sétima edição. Em um país em que a inconclusão da cidadania insiste em se eternizar, parecem revigorar-se a cada momento as concepções de José Murilo de Carvalho.

Como sugere o título, Cidadania no Brasil - o longo caminho, a obra de Murilo de Carvalho diz respeito ao avanço da cidadania no Brasil, enquanto fenômeno histórico. O autor inicia seu trabalho desdobrando a cidadania em três dimensões: direitos civis (direito à liberdade, à propriedade e à igualdade perante a lei); direitos políticos (direito à participação do cidadão no governo da sociedade - voto) e direitos sociais (direito à educação, ao trabalho, ao salário justo, à saúde e à aposentadoria). O objetivo geral do autor é demonstrar que no Brasil não houve um atrelamento dessas três dimensões políticas. O direito a esse ou àquele direito, digamos à liberdade de pensamento e ao voto, não garantiu o direito a outros direitos, por exemplo, à segurança e ao emprego. No mesmo sentido, a agudização dos problemas sociais no país, nos últimos anos, serve de apoio para o autor contrastar as dimensões dos direitos políticos, via sufrágio universal, com os direitos sociais e os direitos civis. A negação desses direitos, vez ou outra no Brasil, é utilizada pelo historiador para dar sustentação à sua tese de que se tem gerado historicamente neste país uma cidadania inconclusa - como na Inglaterra nos séculos XVIII e XIX.

Fundamentado nos estudos de T. A. Marshall sobre a conquista dos direitos na Inglaterra, o historiador mostra que os ingleses introduziram primeiramente os direitos civis, no século XVIII e, somente um século mais tarde - após o exercício à exaustão desses direitos -, os direitos políticos. Os direitos sociais, entretanto, tiveram de esperar mais cem anos até que se fizessem ouvidos. $\mathrm{O}$ fato é que, adverte Murilo de Carvalho, a tentativa simplista de analisar esta questão meramente pelo viés cronológico induzir-nos-ia, entrementes, a simplificações errôneas. Se assim o fizéssemos, seríamos levados a pensar a completude da cidadania no Brasil como ‘uma questão de tempo', quando, na verdade, o diferencial entre a nossa cidadania e a dos ingleses está no fato de que o tripé que compõe a cidadania: direitos políticos, civis e sociais foi por aquele povo conquistado, e a nós ele foi doado, segundo os interesses particulares dos governantes de plantão. Na Inglaterra, a introdução de um direito parecia estar atrelada ao exercício pleno de outro, ou seja, foi exatamente o exercício dos direitos civis que fez com que os ingleses reivindicassem direitos políticos e, daí, os sociais; mas nem por isso seguindo uma mera lógica cronológica. No caso brasileiro, o exercício desses direitos parece não ser ainda uma prática muito freqüente, fazendo-os parecerem distantes da sua plenitude.

O problema central colocado aqui por Murilo de Carvalho - e que parece querer conflitar permanentemente com tentativa do autor de descaracterizar a ordem cronológica como cerne para a organização de uma dada sociedade - é que se não se segue a ordem inglesa, dificilmente se tem o povo no comando de suas demandas políticas. Essa responsabilidade acaba por ficar a cargo de outras instituições. No caso brasileiro, essa tarefa tem sido desenvolvida pelo Estado. A partir desta premissa, Murilo de Carvalho expõe aquela que será a idéia central de seu trabalho, argumentando que a lógica da seqüência descrita por Marshall foi invertida no Brasil: a pirâmide dos direitos foi colocada de cabeça para baixo. Aqui, primeiro vieram os direitos sociais, nos anos 
1930, implantados em período de supressão dos direitos políticos e de redução dos direitos civis por Getúlio Vargas, um ditador que se tornou popular - o que explicaria, em parte, a origem do Estado clientelista no país. O autor verifica que a falta de liberdade política sempre foi compensada pelo autoritarismo do Brasil pós-1930, com o paternalismo social.

Realizando um balanço histórico primoroso, Murilo de Carvalho observa que da passagem do período colonial à independência brasileira, o conjunto de direitos, civis, sociais e políticos, que poderiam gerar um Estado de cidadãos, praticamente inexistia. A própria independência não foi capaz de introduzir mudanças radicais no conjunto desses direitos. Apesar de constituir um avanço no que se refere aos direitos políticos, a independência, feita com a manutenção da escravidão, trazia em si grandes limitações aos direitos civis. Houve, inclusive, retrocesso no que concerne aos direitos políticos, 59 após a independência, pois aos analfabetos não mais foi concedido o direito ao voto. A partir daí, somente os mais abastados e letrados estariam aptos a participar do processo político.

A proclamação da República, em 1889 não alteraria o quadro, traria pouca mudança. A Constituição republicana de 1891, por sua vez, teria um caráter exclusionista: continuaria a excluir do voto os analfabetos, as mulheres, os mendigos, os soldados, os membros das ordens religiosas. Do ponto de vista do avanço da cidadania, naquilo que concerne aos direitos sociais, o mais significativo foi o movimento que pôs fim à Primeira República, em 1930. Desde a independência até 1930, a única alteração importante que houve quanto ao avanço da cidadania foi exatamente a abolição da escravidão, em 1888 - ignorada pela Constituição Liberal de 1824 .

Apostando na tese de que somente o exercício pleno de um direito pode redundar na aquisição de outros direitos, Murilo de Carvalho argumenta que o que obstaculizou a conquista dos direitos sociais no período pós-libertação dos escravos foi exatamente a extremada limitação dos direitos civis, que perduraria até 1930. Ainda que o direito (civil) à liberdade, à não-escravidão, estivesse garantido desde 1888 , os parcos outros direitos civis - e políticos -, supostamente garantidos, eram muitíssimo precários, o que teria retardado, efetivamente, a conquista de direitos sociais.

O argumento de sustentação para a tese do autor é a de que a participação na política nacional, inclusive nos grandes acontecimentos, era limitada a pequenos grupos, sem a presença das massas. Desde os mais remotos tempos coloniais até 1930, não havia povo organizado politicamente nem sentimento nacional consolidado. A grande maioria do povo tinha com o governo uma relação ou de distância ou de antagonismo. Se houve ações políticas do povo, estas eram realizadas como reação ao que considerava arbítrio das autoridades. Era uma "cidadania em negativo". Até 1930, o povo não tinha lugar no sistema político, seja no Império, seja na República, daí não haver lugar para a introdução de direitos, tais como os sociais. Por isso mesmo, sustenta o autor, a queda da Primeira República teria representado um avanço em relação à sua proclamação em 1889. Tal avanço dar-se-ia, se não necessária e imediatamente em direção aos direitos civis e políticos, certamente em direção aos direitos sociais.

Murilo de Carvalho, entretanto, fiel à sua tese inicial - ignorando, pois, a possibilidade de existência de certa ordem cronológica no avanço dos direitos -, define como sendo de baixíssimo impacto o exercício da cidadania no Brasil, no pós-1930. Isso deu-se, segundo o historiador, pelo fato de os direitos sociais terem sido introduzidos antes da expansão dos direitos civis. Os avanços trabalhistas, longe de serem conquistados, foram doados por um governo cooptador - e posteriormente ditatorial - cujos líderes pertenciam às elites tradicionais, sem vinculação autêntica com causas populares. Se por um lado, a expansão dos direitos trabalhistas - sociais - significou efetivamente um avanço da cidadania na medida em que trazia as massas para a política, em contrapartida, criava uma massa de reféns da União e de seus tentáculos regionais. A "doação dos direitos sociais" ao invés da sua conquista fazia com que os direitos fossem percebidos pela população como um favor, colocando os cidadãos em posição de dependência perante os líderes.

Que tipo de cidadania poderia daí resultar? - questiona-se o autor, visto a pirâmide de Marshall não ter base de sustentação no Brasil. Sua resposta é de que o mínimo que se pode esperar é por um enaltecimento do Executivo, em detrimento dos outros dois poderes. Daí o encantamento da população com o uso do "punho forte" do Executivo e seu menosprezo aos demais poderes. Além disso, o Estado passa a ganhar certa supremacia sobre a sociedade civil, o que é terrível, pois, dessa relação é extraída a possibilidade de organização livre e independente das massas, numa espiral viciosa, para a conquista dos direitos. 
O grande dilema que Murilo de Carvalho se coloca dentro dessa perspectiva é justamente sobre o tipo de cidadão e de sociedade que se formam quando a base da pirâmide descrita por Marshall é invertida. A convicção democrática, por certo, conclui o autor, está comprometida, pois entre o Judiciário e o Executivo praticamente não há separação, e, portanto, nenhuma garantia do exercício das liberdades. Daí, sem o exercício das liberdades, dificilmente se chegaria à conquista dos direitos políticos plenos.

No Brasil, entretanto, chegou-se - ainda que esdruxulamente. Eles foram implantados, na segunda metade dos anos 1940, por um militar do exército, o General Eurico Gaspar Dutra, que logo colocaria o Partido Comunista Brasileiro na ilegalidade. Ainda assim, o período democrático entre 1945 e 1964 caracterizara-se pelo oposto ao governo de Vargas. Houve ali uma ampliação dos direitos políticos e paralisação, ou avanço lento, dos direitos sociais. Ainda que os direitos civis fossem relegados ao segundo plano, um observador menos atento ficaria com a impressão de que a lógica da pirâmide de Marshall começava a querer tomar forma. Murilo de Carvalho, no entanto, elucida essa percepção. No período, um ensaio de construção da cidadania dá-se, porém, "de cima para baixo", sem a participação de um povo verdadeiramente organizado. O cidadão em construção ainda não tivera tempo de aprender a ser cidadão, mas a prezar por líderes fortes, geralmente $o$ chefe do Executivo. Tanto é verdadeira a assertiva de Murilo de Carvalho que Getúlio Vargas seria eleito senador por dois Estados, nesse período, e 'voltaria nos braços do povo', em 1951, à presidência da República.

Em 1964, 19 anos após a queda da ditadura Vargas, os direitos civis e políticos seriam novamente sufocados por duras medidas de repressão, admitidas pela apatia popular dos quase cidadãos brasileiros. Dessa vez, a exemplo da Proclamação da República, tomadas pela cúpula militar. Os governos militares, na interpretação de Murilo de Carvalho, repetiriam a tática do Estado Novo, ou seja, enquanto cercearam os direitos políticos e civis, investiram na expansão dos direitos sociais. Dessa vez, no entanto, os órgãos de representação política foram transformados em meras peças decorativas do regime; eles, na prática, não eram representativos de nada e de ninguém.

Na passagem de análise do Movimento de 1964, Murilo de Carvalho coloca-se a seguinte pergunta: por que a democracia foi a pique em 1964, se havia condições tão favoráveis a sua consolidação? O autor sugere que a resposta possa estar na falta de conviç̧ão democrática das elites, tanto de esquerda quanto de direita. Segundo o autor, os dois lados envolveram-se em uma corrida pelo controle do governo que deixava de lado a prática da democracia. Murilo de Carvalho é, no entanto, cuidadoso com a assertiva. Para não escapar à sua tese, o historiador afirma que a falta de convicção democrática não bastaria para explicar o comportamento das lideranças. A resposta mais coerente provavelmente está no fato de o Brasil ainda não contar, no momento do Golpe, com organizações civis fortes e representativas que pudessem refrear o curso da radicalização - toda a organização, sindical, estudantil, institucional, não passava de um "castelo de areia" prestes a ruir ao menor dos sopros. Aqui, o autor mais uma vez ratifica sua crença de que quando os direitos não são plenamente exercidos podem impedir o avanço em direção a outros direitos.

Após 1985, quando da queda do regime militar, os direitos civis estabelecidos antes do regime militar, tais como a liberdade de expressão, de imprensa e de organização, foram recuperados, embora muitos deles, a base da seqüência de Marshall, continuem inacessíveis à maioria da população. Ainda assim, o cerne do problema longe permanece de ser cronológico. A forma esdrúxula como os direitos - que dão sustentação à idéia de cidadania - têm sido introduzidos ou suprimidos no Brasil é que faz a diferença. E muito embora os direitos políticos tenham adquirido amplitude nunca antes atingida a partir de 1988, a democracia política não resolveu os problemas mais urgentes, como a desigualdade e o desemprego. Permanecem os problemas da área social e houve agravamento da situação dos direitos civis no que se refere à segurança individual.

Murilo de Carvalho constata que, muito provavelmente em função da inversão da pirâmide de Marshall justamente pela falta de exercício dos direitos pela população -, o ciclo dos direitos responsáveis pela aquisição da cidadania no Brasil completou-se, mas não consegue atingir vastas partes da população. Se não bastasse, no momento em que o ciclo dos direitos parece tomar forma no Brasil, as rápidas transformações da economia internacional ameaçam essa condição, pois exigem a redução do tamanho do Estado - promotor dos direitos do cidadão.

A conclusão a que chega Murilo de Carvalho é de que o direito a esse ou àquele direito - suponhamos à liberdade de pensamento e ao voto - não é garantia de direito a outros direitos - suponhamos segurança e emprego -, o que tem gerado historicamente, no caso do Brasil, uma cidadania inconclusa. O autor procura mostrar que a garantia de direitos civis ou políticos no Brasil estiveram e estão longe de representar uma 
resolução dos muitos problemas sociais aqui presentes - e a recíproca é verdadeira: eles marcham, segundo o autor, em velocidades díspares. A agudização dos problemas sociais, aliás, tem provado que não há um atrelamento necessário entre aquelas três dimensões políticas, tornando passível, em muitos casos, o retrocesso ou o avanço de um ou de outro direito, determinado pela conveniência da circunstância.

Venceslau Alves de Souza (venceslaud@yahoo.com) é mestre em Ciências Sociais pela Pontifícia Universidade Católica de São Paulo (PUC) e doutorando em Ciências Sociais na mesma instituição. 